\title{
Effect of Chemical Treatment of Flax Fiber and Resin Manipulation on Service Life of Their Composites Using Time-Temperature Superposition
}

\author{
Ali Amiri ${ }^{1}$, Chad A. Ulven ${ }^{1, *}$ and Shanshan Huo ${ }^{2}$ \\ Received: 27 August 2015 ; Accepted: 29 September 2015 ; Published: 13 October 2015 \\ Academic Editors: Alper Ilki and Masoud Motavalli \\ 1 Department of Mechanical Engineering, North Dakota State University, PO Box 6050, \\ Department 2490, Fargo, ND 58108, USA; ali.amiri@ndsu.edu \\ 2 Canadian Light Source Inc., 44 Innovation Boulevard, Saskatoon, SK S7N 2V3, Canada; \\ Shanshan.Huo@lightsource.ca \\ * Correspondence: chad.ulven@ndsu.edu; Tel.: +1-701-231-5641; Fax: +1-701-231-8913
}

\begin{abstract}
In recent years there has been a resurgence of interest in the usage of natural fiber reinforced composites in more advanced structural applications. As a result, the need for improving their mechanical properties, as well as service life modeling and predictions have arisen. In this study effect of alkaline treatment of flax fiber as well as addition of $1 \%$ acrylic resin to vinyl ester on mechanical properties and long-term creep behavior of flax/vinyl ester composites was investigated. To perform the alkaline treatment, fibers were immersed into $1500 \mathrm{~mL}$ of $10 \mathrm{~g} / \mathrm{L}$ sodium hydroxide/ethanol solution at $78{ }^{\circ} \mathrm{C}$ for $2 \mathrm{~h}$. Findings revealed that alkaline treatment was successful in increasing interlaminar shear, tensile and flexural strength of the composite but decreased the tensile and flexural modulus by $10 \%$. Addition of acrylic resin to the vinyl ester resin improved all mechanical properties except the flexural modulus which was decreased by $5 \%$. In order to evaluate the long-term behavior, creep compliance master curves were generated using the time-temperature superposition principle. Results suggests that fiber and matrix treatments delay the creep response and slows the process of creep in flax/vinyl ester composites in the steady state region, respectively.
\end{abstract}

Keywords: alkaline treatment; bio-based composites; creep; flax; resin treatment; time-temperature superposition; vinyl ester

\section{Introduction}

\subsection{Flax Fiber}

Due to their superior advantages, natural fibers, such as flax, have been the center of attention as natural reinforcement in composite materials for the past couple of decades. While natural fibers offer competitive strength-to-weight ratio compared to mineral-based fibers, e.g., glass and basalt, other benefits include reduction in $\mathrm{CO}_{2}$ emission, less dependency on foreign oil sources, reduction in energy consumption, and, the most important one, recyclability [1,2]. There have been numerous studies on natural fiber technology [3-5], as well as their use as reinforcement in polymer composites [6-13].

As shown in Figure 1a there are several layers in a single flax fiber structure [14,15]. In each fiber, the first layer dispositioning during plant growth is a thin primary wall containing both cellulose and hemicellulose and has a thickness of around $0.2 \mu \mathrm{m}[16,17]$. The middle layer of secondary wall, is thicker than first and third layer and contributes to the strength of the fiber. The secondary 
wall includes three layers which consists of helically wound highly crystalline cellulose chains called microfibrils. These microfibrils are made up of 30 to 100 cellulose molecule chains which are oriented with approximately $10^{\circ}$ angle with the axis of the fiber. Smaller microfibrillar angle will result in a more rigid fiber [16]. According to Bledzki et al. [18], the secondary wall contributes to up to $70 \%$ of the fiber Young's modulus, therefore higher cellulose content will result in higher tensile modulus [18].

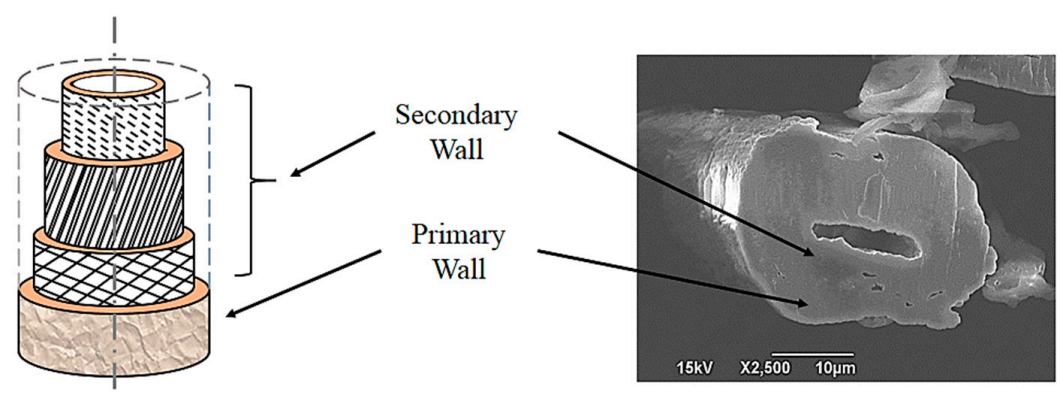

(a)
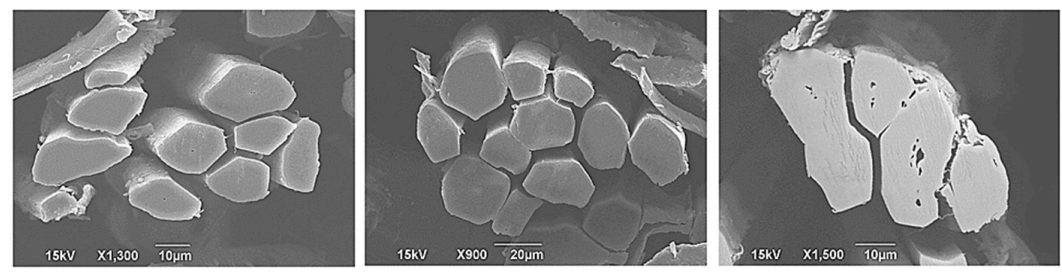

(b)

Figure 1. (a) The structure of a flax fiber cell; (b) cross-section of a bundle of flax fibers.

Similar to other natural fibers, flax does not have a constant longitudinal dimensions (cross section along its length). Hornsby et al. [19], Morvan et al. [20], and Stamboulis et al. [21] mentioned cross section of flax fiber as polygonal with 5-7 sides as is shown in Figure 1b. In general, fibers become thinner as we move from root towards the tip. On average, width of the fiber is $19 \mu \mathrm{m}$ and the length can be up to $33 \mathrm{~mm}[22,23]$.

\subsection{Treatment of Flax Fiber}

In natural fiber reinforced composites, interfacial bonding between fiber and matrix plays a critical role in final composite properties. The hydrophilic nature of flax fiber will lead to absorption of moisture and the result would be presence of voids at the interface of fiber and matrix. Chemical modifications, such as alkaline, coupling agents, and acid treatments, to remove or reduce non-cellulose content will improve mechanical properties of resulting composites by increasing bonding between the matrix and the fiber and reducing moisture absorption of the fiber.

Alkaline treatment is removal of hydrogen bonding in the structure of natural fiber. This will result in increase of amorphous cellulose. The alkaline treatment is a swelling reaction which can be expressed as the following reaction [24]:

$$
\text { Fibe- } \mathrm{OH}+\mathrm{NaOH} \rightarrow \text { Fiber- } \mathrm{O}^{-} \mathrm{Na}^{+}+\mathrm{H}_{2} \mathrm{O}
$$

Use of sodium hydroxide for alkaline treatment will result in higher amount of swelling [25].

Alkaline treatment can serve two purposes. First, it will increase the surface roughness of the fiber. This enhances the interfacial adhesion between fiber and matrix or in other words, it increases the mechanical interlocking. Second, by increasing the amount of exposed cellulose to the surface of the fiber, this treatment increases the number of reaction sites and therefore increases better adhesion between fiber and matrix [24,26]. Cellulose as it occurs in nature has a monoclinic crystalline lattice 
of cellulose-I. By means of different chemical or thermal treatments this structure can be changed into different polymorphous form. Based on Fengel et al. [25], concentration and type of solution used for treatment affects the degree of lattice transformation into cellulose-II.

\subsection{Vinyl Ester}

Vinyl Ester (VE) resins are thermosetting resins, typically a di-ester containing recurring ether linkage. The back bone of VE consists of methacrylate oligomer or acrylate and styrene as a reactive diluent $[27,28]$. Combination of these materials results in combined mechanical and thermal properties of epoxy resins and unsaturated polyester resins, which makes them a great option for high performance fiber reinforced composites [29]. Methacrylate VE resins which contain styrene are typically used in fiberglass reinforced plastics (FRP) and acrylate vinyl ester resins are added during the formulation of UV-cure coatings [27]. Cured VE resins have high resistivity towards solvents, acids and bases. In additions, cured VE has great resistance to degradation in corrosive environments and this makes them suitable for variety of applications such as marine products, i.e., boats, tubs, swimming pools, sewer pipes, and solvent storage tanks [30-32].

In addition to treatment and modification of fibers, another approach to improve the performance of the composite is to modify the matrix [33]. One method is addition of compatibilizers to the resin in order to decrease the interfacial energy and improve the interfacial adhesion of multiphase polymer [34]. For this method, chemical additives are added to the polymer matrix using chemical or physical interactions to improve the adhesion with the fiber. Addition of compatibilizer with the same repeat unit as the initial matrix will reduce the phase separation of the thermoset resin and result in internal stress and improvement of mechanical performance of the matrix [33,35]. Huo et al. $[33,34,36]$ used Acrylic Resin (AR) to manipulate VE system in order to improve mechanical performance of natural fiber reinforced composites. Acrylic resin is a highly viscous liquid, and is used particularly in combination with cellulose nitrate [34].

\subsection{Service Life Prediction}

As the interest in natural fiber reinforced composites is growing, so is the necessity for development of models and methods to predict and capture time-dependent properties of bio-based composites [37]. These data and models are essential to the development of bio-based composites as they facilitate design engineers in the use of bio-based composites in more structural applications [38]. Time-dependent properties of bio-based composites are the result of the viscoelastic nature of both the matrix [39] and the fiber [40]. In recent years, there have been various studies on viscoelastic behavior of bio-based composites [41-45] and long-term behavior of other polymers [46-49]. One way to predict time-dependent behavior in bio-based composites, is through modeling long-term creep behavior. Using accelerated temperature measurements or the time-temperature superposition (TTS) is a method that will enable performing creep tests that correspond to performance of the material under actual temperature and time conditions. Based on TTS, viscoelastic response of a polymer at higher temperature is the equivalent of the response at lower temperature and higher frequency [38]. Therefore, with the application of TTS, time-dependent properties of the material obtained at different temperatures are shifted horizontally and/or vertically to create a master curve. The generated master curve provides long-term information about performance of the material at a reference temperature.

For the validity of the TTS for thermoset resins reinforced with natural fibers to hold, there are some assumptions to consider. TTS is valid when temperature dependence of horizontal shift factors are in the form of either Williams-Landel and Ferry (WLF) [50] or Arrhenius [51] Equations, the creep tests temperature range should be below material degradation, and there should be no residual curing of the resin occurring during the creep tests. In addition, for crystalline and semi-crystalline materials, the deformation should be kept in the linear viscoelastic range by applying low strains [52]. 
The time-temperature superposition principle, its assumptions and creep theories related to bio-based composites are discussed in detail in [52].

There are numerous studies that investigate the effect of fiber treatment on mechanical properties of resulting composites [36,53-56]. However, to the best of authors' knowledge, there are no studies that investigate the effect of these treatments on long-term creep behavior of long continuous natural fibers/thermoset composites. Creep of fiber reinforced composites is a complex phenomenon, which depends on many factors such as elastic and fracture behavior of the fibers, creep behavior of matrix, fiber-matrix interfacial properties, efficiency of load transfer from matrix to fiber and even the geometry and arrangement of the fibers in matrix [38]. Because of the complex structure and composition of flax fiber and different affects that fiber and matrix treatment could have on the behavior of the composites, treatments will affect aforementioned factors. In the current study, two methods of treatments were selected to investigate their effect on mechanical properties of flax reinforced composites as well as long-term performance; alkaline treatment to treat flax fiber as one of the most common treatments used for natural fibers [57], and the addition of acrylic resin to the VE resin in order to improve the adhesion between the fibers and the VE resin. Results provide better insight on which of the mentioned effective factors in long-term behavior is more prone to be affected by these treatments. This information would be essential for engineers and designers for the incorporation of bio-based composites in more structural designs.

\section{Experimental Section}

\subsection{Materials and Methods}

The fiber used in this study was linen flax, farmed and harvested by the University of Saskatchewan, Saskatoon, SK, Canada. Shive (i.e., woody core of the flax stalk) was removed by passing the fiber through a pilot line eight times at Biolin Research, Inc., Saskatoon, SK, Canada. The resin used was vinyl ester (VE) system Hydropel ${ }^{\circledR}$ R037-YDF-40 with $30 \%$ styrene content generously provided by AOC Resins Co. located in Collierville, TN, USA. The hardener was a 2-butanone peroxide (Luperox ${ }^{\circledR}$ DDM-9) solution, which was obtained from Sigma-Aldrich Co., St. Louis, MO, USA. The mixing ratio of VE to hardener was 100 to 1 weight parts. Acronal ${ }^{\circledR} 700 \mathrm{~L}$ was provided by BASF Aktiengesellschaft, Ludwigshafen, Germany. Acronal ${ }^{\circledR} 700 \mathrm{~L}$ is a type of acrylic resin (AR), which is the copolymer from $n$-butyl acrylate and vinyl isobutyl ether.

As mentioned before, to compare the effect of chemical treatments on mechanical performance of flax fiber reinforced composites, alkaline treatment was selected for treating flax fiber. In order to minimize the effect of shrinkage of the fiber as the result of alkaline treatment [36], $\mathrm{NaOH} /$ ethanol solution was used. To perform the alkaline treatment, fibers were immersed into $1500 \mathrm{~mL}$ of $10 \mathrm{~g} / \mathrm{L}$ sodium hydroxide/ethanol solution at $78^{\circ} \mathrm{C}$ for $2 \mathrm{~h}$. Fibers were then washed with distilled water until no color remained in the water. Finally, fibers were dried in the oven at $80^{\circ} \mathrm{C}$ for $24 \mathrm{~h}$.

Composite panels were manufactured using a hand-layup compression molding process. To process the composite panels, $50 \pm 4 \mathrm{~g}$ of fiber roving was processed with a manual drum carder model DC-P05-B/A from Strauch Fiber Equipment Co. located in New Castle, VA, USA. Carded fiber was placed on the mold and resin was poured onto the fiber until the fiber was soaked with resin. A nonporous Polytetrafluoroethylene (PTFE) sheet was placed on top of the fiber and a caul plate with dimensions of $200 \mathrm{~mm} \times 150 \mathrm{~mm}$ was placed on top. The entire lay-up was sealed under a layer of vacuum bagging plastic and five metric tons of force was applied using a shop press. The applied force resulted in 1.6 MPa pressure over the lay-up. Resin soaked fibers were in the mold under mentioned pressure for $24 \mathrm{~h}$ at room temperature and then post cured at $80^{\circ} \mathrm{C}$ for $12 \mathrm{~h}$. In addition, to keep the moisture content of the composite specimens at a minimum level, all test specimens used in this study were placed in the oven at $80^{\circ} \mathrm{C}$ for $24 \mathrm{~h}$ prior to testing. One percent Acrylic resin was also added to the VE resin as a chemical additive to improve the adhesion between the fibers and the resin. Flax/VE with $1 \mathrm{wt} \%$ acrylic resin composites were also processed by the aforementioned process. 


\subsection{Characterization Methods}

\subsubsection{Constituent Analysis}

Chemical analysis was performed on untreated and treated flax fiber by the Department of Animal and Range Sciences at North Dakota State University. Data collected from the chemical analysis included: dry matter content, ash, crude protein, nitrogen, neutral detergent fiber \%, acid detergent fiber $\%$, acid detergent lignin $\%$, calcium, phosphorus, and crude fat.

\subsubsection{Interlaminar Shear Strength Test}

Inter-laminar properties were evaluated by means of short beam shear test in accordance with the ASTM D2344 using an Instron 5567 load frame, by Instron, Norwood, MA, USA. Five specimens were tested for each sample in displacement controlled mode with the rate of displacement of cross-head set to $1 \mathrm{~mm} / \mathrm{min}$.

\subsubsection{Flexural Test}

Three-point bending tests were performed on five specimens from each sample in accordance with the ASTM D790. The cross-head displacement rate was set to $3 \mathrm{~mm} / \mathrm{min}$. Maximum flexural stress and flexural modulus of specimens were calculated based on the ASTM D790.

\subsubsection{Tensile Test}

Five tensile test specimens were prepared according to the ASTM D3039 from each sample. An Instron 5567 load frame was used with cross-head rate of $2 \mathrm{~mm} / \mathrm{min}$. Tensile strength and modulus of elasticity was calculated from results of these tensile tests in accordance with the ASTM D3039.

\subsubsection{Scanning Electron Microscopy (SEM)}

Scanning Electron Microscopy (SEM) images of treated and untreated flax fiber were captured using a JEOL JSM-6490LV scanning electron microscope, by JOEL Solutions for Innovation, Peabody, MA, USA, at an accelerating voltage of $15 \mathrm{kV}$.

\subsubsection{Creep and Thermal Analysis}

Dynamic Mechanical Analyzer (DMA) Q800 by TA Instruments, New Castle, DE, USA, was used in flexural bending mode with constant stress to perform isothermal creep tests. Each specimen was subjected to creep for $10 \mathrm{~min}$ at each temperature step. Starting test temperature was $30^{\circ} \mathrm{C}$ and ending temperature was $110^{\circ} \mathrm{C}$ with temperature steps of $10^{\circ} \mathrm{C}$.

In order to measure the degradation temperature of flax fiber, as well as flax/VE composite, Thermogravimetric Analysis (TGA) was conducted using a TA instrument TGA Q500 with inert atmosphere. Specimens were heated from room temperature to $500{ }^{\circ} \mathrm{C}$ with temperature ramp of $10^{\circ} \mathrm{C} / \mathrm{min}$.

Differential Scanning Calorimetry (DSC) was conducted on composite samples to evaluate degree of cure of $\mathrm{VE}$ and $\mathrm{VE}+\mathrm{AR}$ resins and make sure that no residual cross-linking was present in the material during the creep testing. DSC Q1000 by TA instruments was used to run the analysis. Approximately $10 \mathrm{mg}$ of the material were sealed in aluminum hermetic pans and were analyzed under dry nitrogen purge. Specimens were heated with the rate of $5^{\circ} \mathrm{C} / \mathrm{min}$ from 25 to $200{ }^{\circ} \mathrm{C}$, and cooled down with the same rate to $25^{\circ} \mathrm{C}$. 


\section{Results and Discussion}

\subsection{Mechanical Properties}

SEM images of the cross section as well as surface of untreated fiber and fibers treated with sodium hydroxide are shown in Figure 2. In addition, chemical analysis results of treated and untreated fibers are presented in Table 1. SEM images and chemical constituent analysis reveals that alkaline treatment was successful in reducing amount of ash, proteins and other impurities from the surface of the fiber. In addition, as a result of this treatment the percentage of cellulose has increased by $10 \%$.
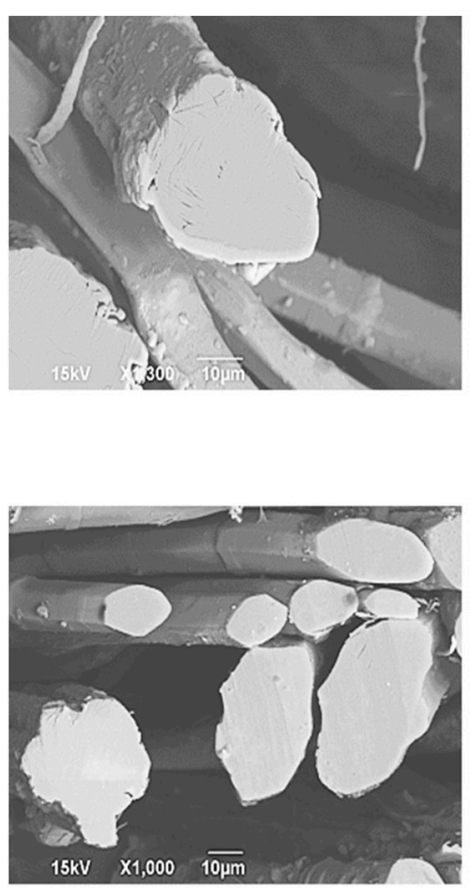

(b)
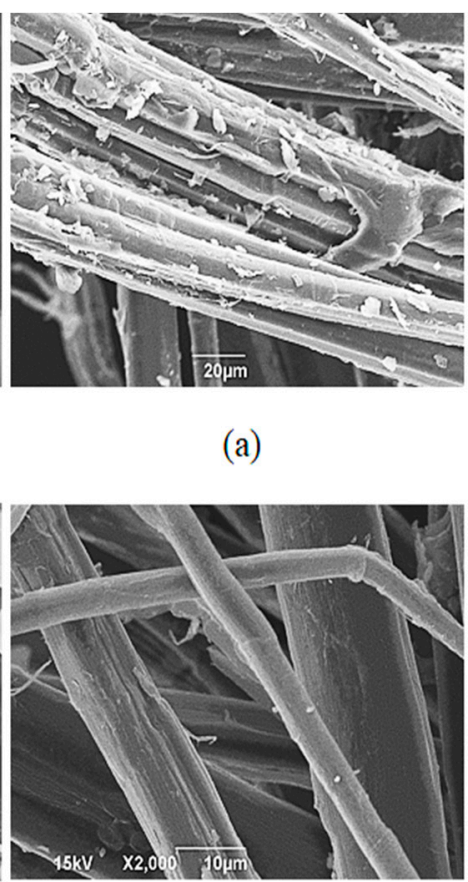

(a)
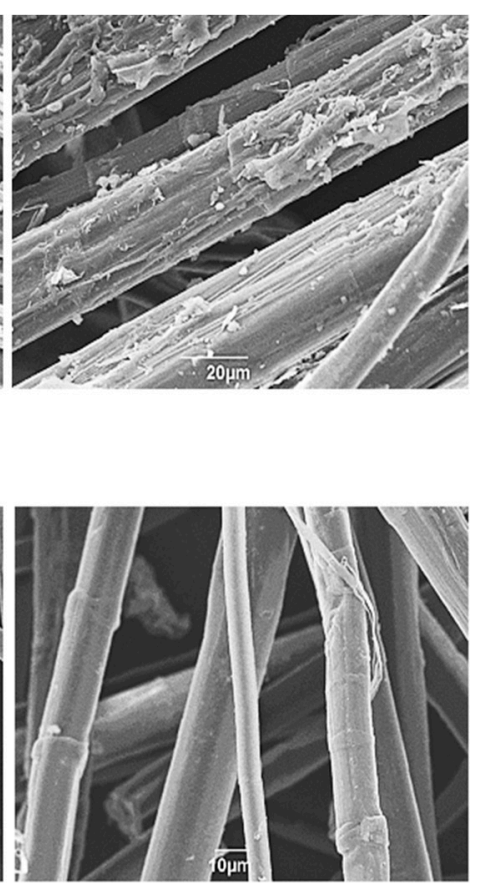

Figure 2. SEM images of flax fiber; (a) untreated; (b) alkaline treated.

Table 1. Constituent analysis of untreated and alkaline treated flax fibers.

\begin{tabular}{|c|c|c|c|c|c|c|c|}
\hline \multirow{2}{*}{ Fiber } & Cellulose & Hemi cellulose & Moisture & Crude protein & Crude fat & Ash & Other \\
\hline & $\%$ & $\%$ & $\%$ & $\%$ & $\%$ & $\%$ & $\%$ \\
\hline Untreated & 79.56 & 8.76 & 2.33 & 2.44 & 0.40 & 1.59 & 0.73 \\
\hline Alkaline Treated & 87.81 & 7.48 & 1.62 & 1.22 & 0.13 & 0.89 & 0.42 \\
\hline
\end{tabular}

The density of flax fiber was measured using gas pycnometery method and was determined to be $1.50 \mathrm{~g} / \mathrm{cm}^{3}$. Immersion density technique was used to measure the density of composite plates and cured resin using a Mettler Toledo 33360 density determination kit (Mettler Toledo, Columbus, $\mathrm{OH}$, USA.) Density of cured VE and VE+AR was measured to be $1.15 \mathrm{~g} / \mathrm{cm}^{3}$. The density of flax/VE and flax/VE+AR composites were between 1.15 and $1.44 \mathrm{~g} / \mathrm{cm}^{3}$, and the fiber volume fraction of the flax fiber composites were found to vary between $35 \%$ and $39 \%$. In order to make the results of mechanical tests comparable, all results were normalized to $35 \%$ fiber volume fraction. The abbreviations used for addressing the different composites and types of specimens used in this study are presented in Table 2 and results of mechanical tests are presents in Table 3 (raw data) and Table 4 (normalized data). 
Table 2. Abbreviations used to describe different composites and specimens used in this study.

\begin{tabular}{ll}
\hline Abbreviation & Description \\
\hline $\mathrm{VE}$ & Vinyl ester resin \\
$\mathrm{AR}$ & Acrylic resin \\
$\mathrm{VE}+\mathrm{AR}$ & Vinyl ester containing $1 \%$ acrylic resin \\
Unt./VE & Vinyl ester resin reinforced with untreated flax fiber \\
Unt./VE+AR & Vinyl ester resin containing 1\% acrylic resin reinforced with untreated flax fiber \\
Alkaline/VE & Vinyl ester resin reinforced with alkaline treated flax fiber \\
Alkaline/VE+AR & Vinyl ester resin containing 1\% acrylic resin reinforced with alkaline treated flax fiber \\
\hline
\end{tabular}

Table 3. Results of mechanical tests for untreated and treated flax fiber with VE and VE+AR resins (raw data).

\begin{tabular}{cccccc}
\hline Composite type & $\begin{array}{c}\text { Interlaminar } \\
\text { shear strength } \\
\text { (MPa) }\end{array}$ & $\begin{array}{c}\text { Tensile strength } \\
\mathbf{( M P a )}\end{array}$ & $\begin{array}{c}\text { Tensile modulus } \\
\mathbf{( G P a )}\end{array}$ & $\begin{array}{c}\text { Flexural strength } \\
\text { (MPa) }\end{array}$ & $\begin{array}{c}\text { Flexural modulus } \\
\mathbf{( G P a )}\end{array}$ \\
\hline Unt./VE & $12.22 \pm 0.92$ & $100.49 \pm 11.02$ & $13.71 \pm 2.10$ & $153.25 \pm 29.90$ & $12.50 \pm 2.90$ \\
Unt./VE+AR & $15.03 \pm 0.95$ & $101.71 \pm 3.21$ & $15.03 \pm 2.12$ & $145.47 \pm 6.79$ & $11.16 \pm 0.70$ \\
Alkaline/VE & $21.48 \pm 1.37$ & $108.33 \pm 2.90$ & $12.38 \pm 1.72$ & $167.69 \pm 10.56$ & $11.13 \pm 1.19$ \\
Alkaline/VE+AR & $18.89 \pm 1.98$ & $100.20 \pm 0.10$ & $11.99 \pm 0.14$ & $135.46 \pm 17.23$ & $11.67 \pm 0.94$ \\
\hline
\end{tabular}

Table 4 and Figure 3 show the normalized interlaminar shear strength for untreated and treated flax fiber composites. Both fiber and matrix treatments were effective in increasing interlaminar shear strength. In other words, both treatments were successful in improving bonding between fiber and the matrix as the fiber-to-matrix bonding defines the interfacial and shear properties [58]. Comparing Unt./VE and Alkaline/VE composites, gains of 70\% is observed for alkaline treatment.

Table 4. Normalized results of mechanical tests for untreated and treated flax fiber with VE and $\mathrm{VE}+\mathrm{AR}$ resins.

\begin{tabular}{cccccc}
\hline Composite type & $\begin{array}{c}\text { Interlaminar } \\
\text { shear strength } \\
\mathbf{( M P a )}\end{array}$ & $\begin{array}{c}\text { Tensile strength } \\
\mathbf{( M P a )}\end{array}$ & $\begin{array}{c}\text { Tensile modulus } \\
\mathbf{( G P a )}\end{array}$ & $\begin{array}{c}\text { Flexural strength } \\
\mathbf{( M P a )}\end{array}$ & $\begin{array}{c}\text { Flexural modulus } \\
\mathbf{( G P a )}\end{array}$ \\
\hline Unt./VE & $12.22 \pm 0.92$ & $100.49 \pm 11.02$ & $13.71 \pm 2.10$ & $153.25 \pm 29.90$ & $12.50 \pm 2.90$ \\
Unt./VE+AR & $15.94 \pm 1.01$ & $107.87 \pm 3.40$ & $15.94 \pm 2.25$ & $154.29 \pm 7.20$ & $11.84 \pm 0.75$ \\
Alkaline/VE & $20.88 \pm 0.93$ & $105.32 \pm 2.82$ & $12.04 \pm 1.67$ & $163.03 \pm 10.27$ & $10.82 \pm 1.16$ \\
Alkaline/VE+AR & $22.04 \pm 2.31$ & $116.90 \pm 0.12$ & $13.99 \pm 0.17$ & $158.04 \pm 20.10$ & $13.62 \pm 1.10$ \\
\hline
\end{tabular}

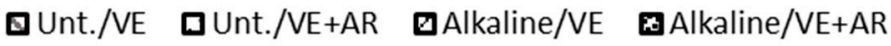

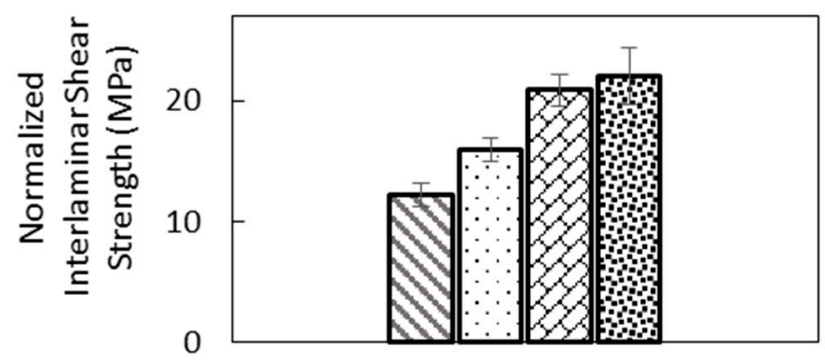

Figure 3. Normalized plots of Interlaminar shear strength for different composites.

Addition of AR resin to VE has increased interlaminar shear strength by $30 \%$ for untreated and alkaline treated flax fiber composites. An increase of over $80 \%$ in interlaminar shear strength 
is observed for alkaline treatment with addition of $1 \%$ AR to VE. Alkaline treatment will hydrolyze pectin in flax fiber and also remove waxes, dyes and ashes from the fiber surface to result in surface roughness and potentially better adhesion between fiber and matrix [54,59]. As also seen in Table 1, alkaline treatment of flax fiber has resulted in $55 \%$ reduction of ash on the surface of the fiber.

Flexural properties of untreated and treated flax fiber with VE and VE+AR resins are presented in Table 4 and Figure 4 . Alkaline treatment has improved the flexural strength by $5 \%$ compared to composites using untreated flax fiber. Addition of the AR to the VE resin has resulted in only a $2 \%$ improvement of flexural strength. Fiber treatment or addition of AR to the matrix has resulted in decrease of flexural modulus. However, when both treatments are combined, flexural modulus is increased by $5 \%$. Similar results were observed in the study done by Huo et al. [34,36]. Alkaline treatment of North American (NA) flax had 5\%-10\% increasing effect on flexural strength. Flexural modulus, on the other hand was decreased by alkaline treatment. The decrease in flexural strength is attributed to the structural variation in the structure of flax fiber. This is the result of non-cellulosic content of the flax fiber and microfibrils losing their resistance to deformation and elongation after treatment [60].

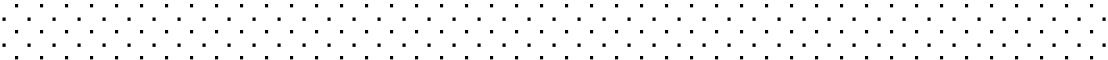

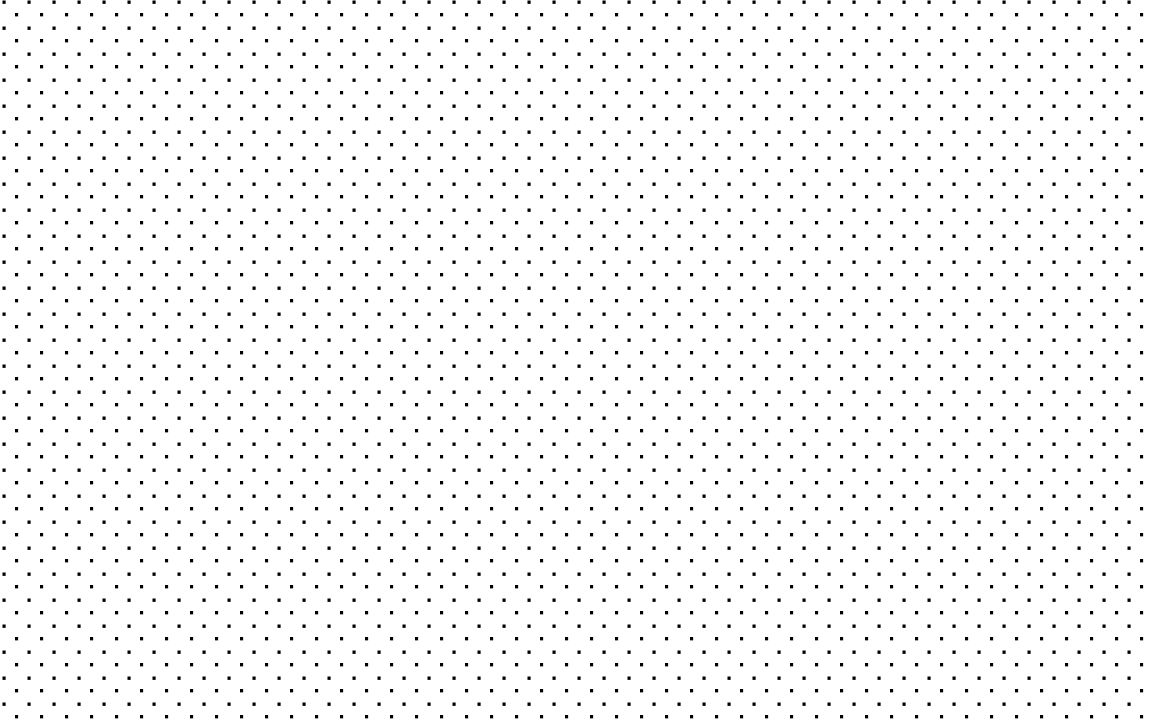

Figure 4. Normalized fleaxural strength and flexural modulus of untreated and treated flax/VE composites.

Tensile properties of untreated and treated flax fiber with VE and VE+AR are presented in Table 4 and Figure 5. Addition of AR to the VE resin has increased the tensile strength between $8 \%$ and $11 \%$ for untreated and alkaline treated flax fiber composites, respectively. This is the indication that as expected, addition of AR has improved the efficiency of load transfer to the matrix [36]. Alkaline treatment has been effective in increasing tensile strength of the composite by $5 \%$ and when combined with the addition of AR to the resin, the increase in tensile strength is $17 \%$ resulting in the highest tensile strength. This increase in tensile strength can be attributed to the enhanced crystallinity and structure of the cellulose after alkaline treatment as seen in Table 1 [61].

Tensile modulus of fiber shows decrease after alkaline treatment. This is known to happen for flax fiber after alkaline treatment $[33,34,36,55]$. This decrease is attributed to the breakdown of the flax fiber after alkaline treatment [34], also structural variation in natural fibers will lead to change in the tensile modulus after treatment [62]. 


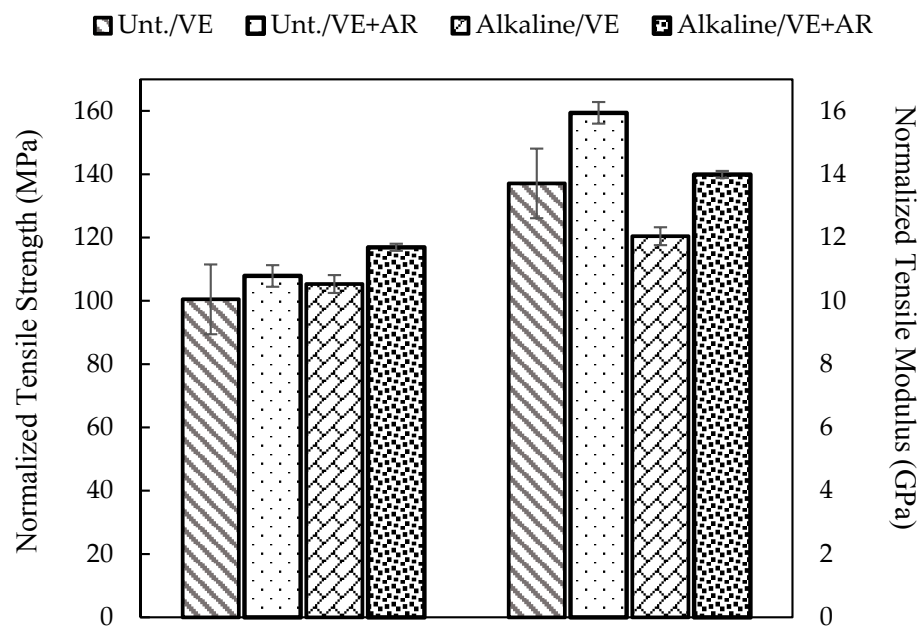

Figure 5. Normalized tensile strength and tensile modulus of untreated and treated flax/VE composites.

\subsection{Thermal and Creep Analysis}

Glass transition temperature of cured VE (Hydropel ${ }^{\circledR}$ R037-YDF-40 with 30\% styrene content) is reported in [52] to be $126.85{ }^{\circ} \mathrm{C}$ and cured VE+AR (Hydropel ${ }^{\circledR}$ R037-YDF-40 with $30 \%$ styrene content with $1 \%$ Acronal ${ }^{\circledR} 700 \mathrm{~L}$ ) is reported by Huo et al. to be $127^{\circ} \mathrm{C}$ [36].

Typical thermal behavior of flax/VE and flax/VE+AR, also, a typical DSC trace for heating of flax/VE and flax/VE+AR are presented in Figure $6 a, b$. As mentioned before, the creep measurements are valid if there is no residual curing happening during creep tests and there is no structure change in the material under study, and the specimen is not degrading in the temperature range.

The degree of cure of resin was calculated using the following Equation [52]:

$$
\text { Degree of cure }=\frac{\Delta H_{\text {reaction }}-\Delta H_{\text {res }}}{\Delta H_{\text {reaction }}}
$$

where $\Delta H_{\text {reaction }}$ is the total heat of reaction and $\Delta H_{\text {res }}$ is the residual heat after curing. In Figure 6a, there was some residual curing approximately around 136 and $138{ }^{\circ} \mathrm{C}$ and the degree of cure for VE and VE+AR was calculated to be $99.40 \%$ and $99.61 \%$, respectively. On TGA curves, as seen in Figure $6 \mathrm{~b}$, addition of AR to VE has not changed the degradation temperature of flax/VE composites and it starts to degrade around $320^{\circ} \mathrm{C}$.

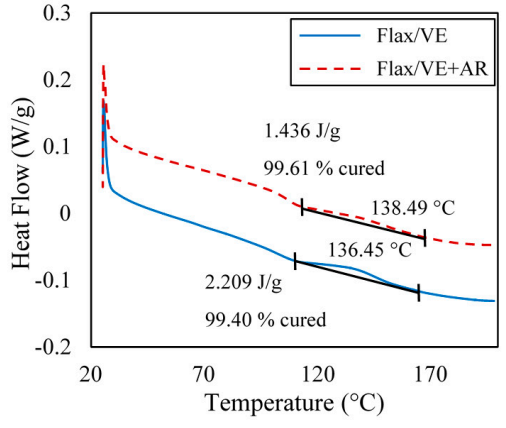

(a)

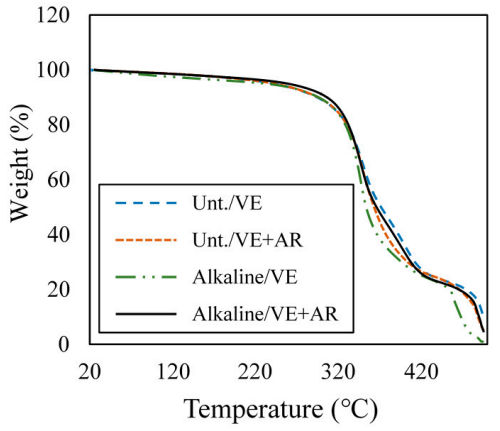

(b)

Figure 6. (a) Typical DSC trace for heating and cooling of flax/VE and flax/VE+AR; (b) typical TGA curves of flax/VE and flax/VE+AR.

Creep behavior of untreated and alkaline treated flax with VE and VE+AR composites are presented in Figure 7. Similar to the work presented in [52] creep compliance master curves 
are generated by shifting the individual creep compliance curves at different temperatures along logarithmic time axis. Creep compliance curve at $30^{\circ} \mathrm{C}$ was selected as the reference curve and all other curves were shifted to the right. Resulted creep compliance master curves are presented in Figure 8 . The curves presented are normalized to $35 \%$ fiber volume fraction to be comparable.
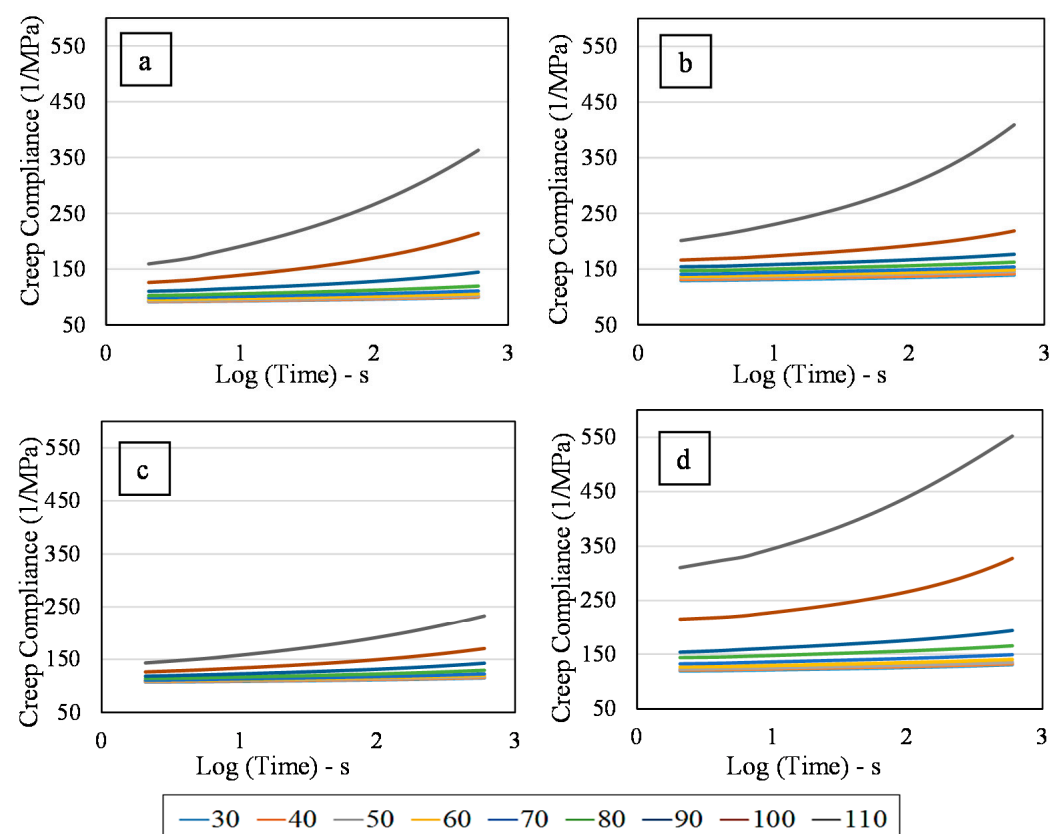

Figure 7. Creep Compliance of (a) Unt./VE; (b) Unt./VE+AR; (c) Alkaline/VE; (d) Alkaline/VE+AR at different temperatures.

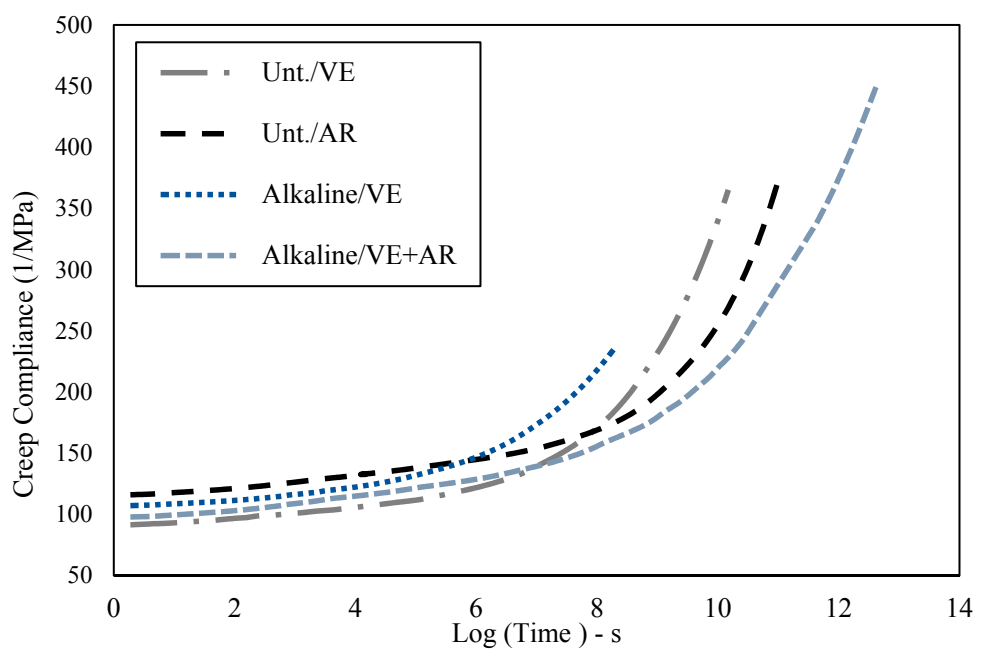

Figure 8. Creep compliance master curves for untreated and treated flax fiber with VE and $\mathrm{VE}+\mathrm{AR}$ resins.

In Figure 8, up to $10^{4.5}, 10^{6} \mathrm{~s}$, can be considered as steady state creep for Alkaline/VE and Unt./VE, respectively. For the composites with VE+AR resin up to $10^{6.5}$ can be considered as steady state region. The slope of the steady state region is the creep rate. Based on the slopes calculated from the steady state of the curves, the highest to the lowest creep rates are Alkaline/VE+AR, Unt./VE+AR, Unt./VE and Alkaline/VE, respectively. In general, composites with neat VE has lower 
strain rate in the steady state region, but composites with VE+AR has longer steady state region and the onset of tertiary state has been retarded.

As seen in Figure 8, the composite with alkaline treatment and addition of AR has the lowest amount of creep after $10^{8} \mathrm{~s}$. This is consistent with results presented in Figure 4 . As observed, alkaline treatment and addition of AR to VE resulted in the highest amount of flexural modulus. However, after $10^{8}$ the rate that the composite with untreated fiber and VE resin starts to creep faster and the order of creep curves is changed.

It is known that increasing the degree of crosslinking of a polymer pushes for the secondary bonding between polymer chains and consequently the polymer becomes more resistant to creep [63]. Addition of AR to VE resin will result in decreasing cross-linking density of the matrix [36], therefore it is expected for the composites using $\mathrm{VE}+\mathrm{AR}$ to exhibit less resistance to creep. Interestingly this is not the case here. As mentioned before, creep of fiber reinforced composites is a complex phenomenon which depends on many factors such as creep behavior of matrix, fiber-matrix interfacial properties and load transfer from matrix to fiber [38]. As observed in the results of interlaminar shear strength, addition of AR to VE resin has resulted in an increase in the interfacial bonding between fiber and matrix. In addition, as observed in the results of tensile strength, addition of AR to VE increased the efficiency of load transfer to the matrix. From the results presented in Figure 8, it is perceived that the resultant of the effects of three factors (creep behavior of matrix, fiber-matric interfacial properties and load transfer from matric to fiber) has been higher resistance of composite to creep after addition of AR to VE resin.

According to William Findley [64], the time-dependent creep compliance of a material can be represented by the following equation known as Findley Power Law Equation:

$$
J=J_{o}+J(t)=J_{0}+A t^{n}
$$

where $A$ is the time-dependent coefficient, $t$ is the time and $n$ is the stress-independent coefficient and $J_{0}$ is the time-independent or elastic creep compliance. For each generated master curve, Findley Power Law Equation (3) was adapted. Calculated coefficients and R-square of the fits are presented in Table 5.

Table 5. Parameters in Findley Power Law equation for different composites under study.

\begin{tabular}{ccccc}
\hline Composite & $\boldsymbol{J}_{\boldsymbol{0}} \mathbf{( 1 / M P a )}$ & $\boldsymbol{A}$ & $\boldsymbol{n}$ & $\mathbf{R}^{\mathbf{2}}$ \\
\hline Unt./VE & $100.8 \pm 1.4$ & $0.00135 \pm 0.0003$ & $5.24 \pm 0.154$ & 0.9960 \\
Unt./VE+AR & $126.2 \pm 1.7$ & $0.00135 \pm 0.003$ & $5.007 \pm 0.012$ & 0.9961 \\
Alkaline/VE & $117.5 \pm 1.2$ & $0.00135 \pm 0.003$ & $5.418 \pm 0.073$ & 0.9966 \\
Alkaline/VE+AR & $112.8 \pm 2.1$ & $0.00135 \pm 0.003$ & $4.903 \pm 0.082$ & 0.9957 \\
\hline
\end{tabular}

As mentioned, $A$ is temperature-independent variable, so in the curve fitting process, $A$ was kept at a constant value of 0.00135 which was calculated for Unt./VE composites at $30{ }^{\circ} \mathrm{C}$. As seen in Figure 8, master curves for composites with VE resin are parallel to each other with the values of stress-independent coefficient of $n=5.24$ for untreated and $n=5.418$ for alkaline treated flax fiber. Likewise, curves for VER+AR reinforced with flax are parallel to each other with the values of $n=5.007$ for untreated and $n=4.903$ for alkaline treated flax fibers. Therefore, addition of AR to VE has resulted in the reduction of the stress-independent coefficient.

\section{Conclusions}

Mechanical properties of untreated and alkaline treated flax fiber with vinyl ester resin and vinyl ester containing $1 \%$ acrylic resin were investigated using static mechanical tests. Alkaline treatment was successful in increasing interlaminar shear strength and tensile and flexural strength of the composites. On the other hand, both tensile and flexural modulus of composites using alkaline 
treated flax fiber were decreased. Addition of $1 \%$ acrylic resin to the resin was effective in improving all mechanical properties except for flexural modulus where a decrease of $10 \%$ in modulus was observed. For all mechanical properties, the highest gain was observed where vinyl ester containing $1 \%$ acrylic resin was reinforced with alkaline treated flax fiber except for tensile modulus.

Time temperature superposition (TTS) principle was applied to the results of creep compliance measurements at different temperatures to evaluate the effect of fiber and matrix treatment on long-term creep behavior. Results revealed that addition of acrylic resin to vinyl ester, slowed the process of creep in flax/vinyl ester composites in the steady state region. Moreover, combining alkaline treatment of flax fiber with manipulation of vinyl ester resin by addition of $1 \%$ acrylic resin delayed and extended creep response. In other words, by comparing creep compliance curves of untreated composites with composites using treatment of flax and vinyl ester, the former reached creep compliance of $3501 / \mathrm{MPa}$ after $10^{10} \mathrm{~s}$, where the latter reached the same value after $10^{12} \mathrm{~s}$.

Acknowledgments: This material is based upon work supported by the National Science Foundation, USA, under Grant No. NSF EPSCoR Award IIA-1355466 and NSF EPSCoR Award EPS-0814442 and Composites Innovation Center, Manitoba, Canada.

Author Contributions: Ali Amiri has performed the tests, analyzed the results, and has written the paper with the advice of Chad Ulven; Chad Ulven, has analyzed the results and edited the paper; Shanshan Huo has developed the treatment process and has performed the fiber treatment.

Conflicts of Interest: The authors declare no conflict of interest.

\section{References}

1. Fowler, P.A.; Hughes, J.M.; Elias, R.M. Biocomposites: Technology, environmental credentials and market forces. J. Sci. Food Agric. 2006, 86, 1781-1789. [CrossRef]

2. Amiri, A.; Ulven, C. Surface Treatment of Flax Fiber. In Proceedings of the 65th Flax Institute of the United States, Fargo, ND, USA, 27-28 March 2014; pp. 117-125.

3. Chand, N.; Tiwary, R.; Rohatgi, P. Bibliography resource structure properties of natural cellulosic fibres-An annotated bibliography. J. Mater. Sci. 1988, 23, 381-387. [CrossRef]

4. Lilholt, H.; Lawther, J. Natural organic fibers. Compr. Compos. Mater. 2000, 1, 303-325.

5. Franck, R.R. Bast and Other Plant Fibres; CRC Press: Boca Raton, FL, USA, 2005; Volume 39.

6. Bolton, A. Natural fibers for plastic reinforcement. Mater. Technol. USA 1994, 9, 12-20.

7. Saheb, D.N.; Jog, J. Natural fiber polymer composites: A review. Adv. Polym. Technol. 1999, 18, 351-363. [CrossRef]

8. Mohanty, A.; Misra, M. Studies on jute composites-A literature review. Polym. Plast. Technol. Eng. 1995, 34, 729-792. [CrossRef]

9. Bledzki, A.K.; Sperber, V.; Faruk, O. Natural and Wood Fibre Reinforcement in Polymers; Rapra Technology LTD.: Shrewsbury, Shropshire, UK, 2002; Volume 13.

10. Netravali, A.N.; Chabba, S. Composites get greener. Mater. Today 2003, 6, 22-29. [CrossRef]

11. Baillie, C. Green Composites: Polymer Composites and the Environment; CRC Press: New York, NY, USA, 2004.

12. Mohanty, A.K.; Misra, M.; Drzal, L.T. Natural Fibers, Biopolymers, and Biocomposites; CRC Press: Boca Raton, FL, USA, 2005.

13. Pickering, K. Properties and Performance of Natural-Fibre Composites; CRC Press: Boca Raton, FL, USA, 2008.

14. Rong, M.Z.; Zhang, M.Q.; Liu, Y.; Yang, G.C.; Zeng, H.M. The effect of fiber treatment on the mechanical properties of unidirectional sisal-reinforced epoxy composites. Compos. Sci. Technol. 2001, 61, 1437-1447. [CrossRef]

15. Bowes, B.G. A Colour Atlas of Plant Structure; Manson Publishing Ltd.: London, UK, 1996.

16. Bos, H.; Donald, A. In situ ESEM study of the deformation of elementary flax fibres. J. Mater. Sci. 1999, 34, 3029-3034. [CrossRef]

17. Amiri, A.; Hosseini, N.; Ulven, C.; Webster, D. Advanced Bio-composites made from methacrylated epoxidized sucrose soyate resin reinforced with flax fibers. In Proceedings of the 20th International Conference on Composite Materials, Copenhagen, Denmark, 19-24 July 2015; BytePress: Copenhagen, Denmark, 2015; p. 3503. 
18. Bledzki, A.; Gassan, J. Composites reinforced with cellulose based fibres. Prog. Polym. Sci. 1999, 24, $221-274$. [CrossRef]

19. Hornsby, P.; Hinrichsen, E.; Tarverdi, K. Preparation and properties of polypropylene composites reinforced with wheat and flax straw fibres: Part I fibre characterization. J. Mater. Sci. 1997, 32, 443-449. [CrossRef]

20. Morvan, C.; Andème-Onzighi, C.; Girault, R.; Himmelsbach, D.S.; Driouich, A.; Akin, D.E. Building flax fibres: More than one brick in the walls. Plant Physiol. Biochem. 2003, 41, 935-944. [CrossRef]

21. Stamboulis, A.; Baillie, C.; Peijs, T. Effects of environmental conditions on mechanical and physical properties of flax fibers. Compos. Appl. Sci. Manuf. 2001, 32, 1105-1115. [CrossRef]

22. Baley, C. Analysis of the flax fibres tensile behaviour and analysis of the tensile stiffness increase. Compos. Appl. Sci. Manuf. 2002, 33, 939-948. [CrossRef]

23. Rowell, R. Natural fibres: Types and properties. In Properties and Performance of Natural-Fibre Composites; CRC Press: New York, NY, USA, 2008; pp. 3-66.

24. Li, X.; Tabil, L.G.; Panigrahi, S. Chemical treatments of natural fiber for use in natural fiber-reinforced composites: A review. J. Polym. Environ. 2007, 15, 25-33. [CrossRef]

25. Fengel, D.; Wegener, G. Wood: Chemistry, Ultrastructure, Reactions; Walter de Gruyter \& Co.: Berlin, Germany, 1983.

26. Valadez-Gonzalez, A.; Cervantes-Uc, J.; Olayo, R.; Herrera-Franco, P. Effect of fiber surface treatment on the fiber-matrix bond strength of natural fiber reinforced composites. Compos. Part B 1999, 30, 309-320. [CrossRef]

27. TP, O.H. Vinyl esters in engineered materials handbook. Eng. Plast. 1988, 2, 272-275.

28. Scott, T.F.; Cook, W.D.; Forsythe, J.S. Kinetics and network structure of thermally cured vinyl ester resins. Eur. Polym. J. 2002, 38, 705-716. [CrossRef]

29. Åström, B.T. Manufacturing of Polymer Composites; CRC Press: Cheltenham, UK, 1997.

30. Morton, M.D; Denn, M.M. Encyclopedia of polymer science and engineering. Vols. 1-10: A-pentadiene polymers by H. F. Mark, N. M. Bikales, C. G. Overberger, and G. Menges, eds., J. I. Kroschwitz, editor-in-chief, Wiley-Interscience, New York, 2nd ed.,1985-1987,approx.. 820 pp/vol. \$200.00/vol. AIChE J. 1988, 34, 1051-1052.

31. Marsh, G. Vinyl ester-The midway boat building resin. Reinf. Plast. 2007, 51, 20-23. [CrossRef]

32. Taillemite, S.; Pauer, R. Bright future for vinyl ester resins in corrosion applications. Reinf. Plast. 2009, 53, 34-37. [CrossRef]

33. Huo, S. The Physico-Chemical Investigation of Interfacial Properties in Natural Fiber/Vinyl Ester Biocomposites. Ph.D. Thesis, North Dakota State University, Fargo, ND, USA, 2012.

34. Huo, S.; Fuqua, M.; Chevali, V.S.; Ulven, C.A. Effects of natural fiber surface treatments and matrix modification on mechanical properties of their composites. SAE Tech. Paper 2010. [CrossRef]

35. Antonucci, V.; Cusano, A.; Giordano, M.; Nasser, J.; Nicolais, L. Cure-induced residual strain build-up in a thermoset resin. Compos. Appl. Sci. Manuf. 2006, 37, 592-601. [CrossRef]

36. Huo, S.; Chevali, V.S.; Ulven, C.A. Study on interfacial properties of unidirectional flax/vinyl ester composites: Resin manipulation on vinyl ester system. J. Appl. Polym. Sci. 2013, 128, 3490-3500. [CrossRef]

37. Miller, S.A.; Srubar, W.V.; Billington, S.L.; Lepech, M.D. Integrating durability-based service-life predictions with environmental impact assessments of natural fiber-reinforced composite materials. Resour. Conserv. Recycl. 2015, 99, 72-83. [CrossRef]

38. Guedes, R.M. Creep and Fatigue in Polymer Matrix Composites; Woodhead Publishing Limited: Philadelphia, PA, USA, 2010.

39. Hearle, J. The fine structure of fibers and crystalline polymers. III. Interpretation of the mechanical properties of fibers. J. Appl. Polym. Sci. 1963, 7, 1207-1223. [CrossRef]

40. Keryvin, V.; Lan, M.; Bourmaud, A.; Parenteau, T.; Charleux, L.; Baley, C. Analysis of flax fibres viscoelastic behaviour at micro and nano scales. Compos. Appl. Sci. Manuf. 2015, 68, 219-225. [CrossRef]

41. Kontou, E.; Spathis, G.; Georgiopoulos, P. Modeling of nonlinear viscoelasticity-viscoplasticity of bio-based polymer composites. Polym. Degrad. Stab. 2014, 110, 203-207. [CrossRef]

42. Joffe, R.; Rozite, L.; Pupurs, A. Nonlinear behavior of natural fiber/bio-based matrix composites. In Challenges in Mechanics of Time-Dependent Materials and Processes in Conventional and Multifunctional Materials; Springer: New York, NY, USA, 2013; Volume 2, pp. 131-137. 
43. Pupure, L.; Joffe, R.; Varna, J.; Nyström, B. Development of constitutive model for composites exhibiting time dependent properties. IOP Conf. Ser. Mater. Sci. Eng. 2013, 48, 012007. [CrossRef]

44. Song, Y.S.; Lee, J.T.; Ji, D.S.; Kim, M.W.; Lee, S.H.; Youn, J.R. Viscoelastic and thermal behavior of woven hemp fiber reinforced poly (lactic acid) composites. Compos. Part B 2012, 43, 856-860. [CrossRef]

45. Yang, H.-S.; Gardner, D.J.; Kim, H.-J. Viscoelastic and thermal analysis of lignocellulosic material filled polypropylene bio-composites. J. Therm. Anal. Calorim. 2009, 98, 553-558. [CrossRef]

46. Pedrazzoli, D.; Pegoretti, A. Long-term creep behavior of polypropylene/fumed silica nanocomposites estimated by time-temperature and time-strain superposition approaches. Polym. Bull. 2014, 71, 2247-2268. [CrossRef]

47. Dorigato, A.; Pegoretti, A.; Kolařík, J. Nonlinear tensile creep of linear low density polyethylene/fumed silica nanocomposites: Time-strain superposition and creep prediction. Polym. Compos. 2010, 31, 1947-1955. [CrossRef]

48. Kolařík, J.; Pegoretti, A. Non-linear tensile creep of polypropylene: Time-strain superposition and creep prediction. Polymer 2006, 47, 346-356. [CrossRef]

49. Kolařík, J.; Pegoretti, A. Proposal of the boltzmann-like superposition principle for nonlinear tensile creep of thermoplastics. Polym. Test. 2008, 27, 596-606. [CrossRef]

50. Williams, M.L.; Landel, R.F.; Ferry, J.D. The temperature dependence of relaxation mechanisms in amorphous polymers and other glass-forming liquids. J. Am. Chem. Soc. 1955, 77, 3701-3707. [CrossRef]

51. Tajvidi, M.; Falk, R.H.; Hermanson, J.C. Time-temperature superposition principle applied to a kenaf-fiber/high-density polyethylene composite. J. Appl. Polym. Sci. 2005, 97, 1995-2004. [CrossRef]

52. Amiri, A.; Hosseini, N.; Ulven, C.A. Long-term creep behavior of flax/vinyl ester composites using time-temperature superposition principle. J. Renew. Mater. 2015, 3, 224-233. [CrossRef]

53. Huo, S.; Thapa, A.; Ulven, C. Effect of surface treatments on interfacial properties of flax fiber-reinforced composites. Adv. Compos. Mater. 2013, 22, 109-121. [CrossRef]

54. Van de Weyenberg, I.; Chi Truong, T.; Vangrimde, B.; Verpoest, I. Improving the properties of UD flax fibre reinforced composites by applying an alkaline fibre treatment. Compos. Appl. Sci. Manuf. 2006, 37, 1368-1376. [CrossRef]

55. Nosbi, N.; Akil, H.M.; Ishak, Z.M.; Bakar, A.A. Degradation of compressive properties of pultruded kenaf fiber reinforced composites after immersion in various solutions. Mater. Des. 2010, 31, 4960-4964. [CrossRef]

56. Whitacre, R.; Amiri, A.; Ulven, C. The effects of corn zein protein coupling agent on mechanical properties of flax fiber reinforced composites. Ind. Crops Prod. 2015, 77, 232-238. [CrossRef]

57. Arbelaiz, A.; Fernandez, B.; Cantero, G.; Llano-Ponte, R.; Valea, A.; Mondragon, I. Mechanical properties of flax fibre/polypropylene composites. Influence of fibre/matrix modification and glass fibre hybridization. Compos. Appl. Sci. Manuf. 2005, 36, 1637-1644. [CrossRef]

58. Scott, T.F.; Cook, W.D.; Forsythe, J.S. Photo-DSC cure kinetics of vinyl ester resins II: Influence of diluent concentration. Polymer 2003, 44, 671-680. [CrossRef]

59. Kushwaha, P.K.; Kumar, R. Influence of chemical treatments on the mechanical and water absorption properties of bamboo fiber composites. J. Reinf. Plast. Compos. 2011, 30, 73-85. [CrossRef]

60. Zhu, J.; Imam, A.; Crane, R.; Lozano, K.; Khabashesku, V.N.; Barrera, E.V. Processing a glass fiber reinforced vinyl ester composite with nanotube enhancement of interlaminar shear strength. Compos. Sci. Technol. 2007, 67, 1509-1517. [CrossRef]

61. Michell, A.J. Second derivative FT-IR spectra of celluloses I and II and related mono-and oligo-saccharides. Carbohydr. Res. 1988, 173, 185-195. [CrossRef]

62. Barkakaty, B. Some structural aspects of sisal fibers. J. Appl. Polym. Sci. 1976, 20, 2921-2940. [CrossRef]

63. Meyers, M.A.; Chawla, K.K. Mechanical Behavior of Materials; Cambridge University Press: Cambridge, UK, 2009; Volome 547.

64. Findley, W.N.; Lai, J.S.; Onaran, K. Creep and Relaxation of Nonlinear Viscoelastic Materials; North-Holland Publishing Company: Amsterdam, The Netherland, 1976; Volume 18.

(C) 2015 by the authors; licensee MDPI, Basel, Switzerland. This article is an open access article distributed under the terms and conditions of the Creative Commons by Attribution (CC-BY) license (http:/ / creativecommons.org/licenses/by/4.0/). 